\title{
Predictors of Perceived Salt Intake and Actual Salt Intake in Romania Implications for public policy
}

\author{
CORINA ILINCA ${ }^{1 *}$, MARIAN PREDA ${ }^{1}$, STEFANIA MATEI ${ }^{2}$, STEPHEN J. CUTLER ${ }^{3}$, OANA TAUTU4, MARIA DOROBANTU 4 \\ ${ }^{1}$ University of Bucharest, Faculty of Sociology and Social Work9 Schitu Magureanu Str., Bucharest, Romania \\ ${ }^{2}$ Research Institute of the University of Bucharest, Division of Social Sciences, 36-46 Bd. M. Kogalniceanu, Bucharest, Romania \\ ${ }^{3}$ Department of Sociology, University of Vermont, Burlington, VT, USA 05405 and Faculty of Sociology and Social Work, University \\ of Bucharest, 9 Schitu Magureanu Str., Bucharest, Romania \\ ${ }^{4}$ Carol Davila University of Medicine and Pharmacy, 37 Dionisie Lupu, Bucharest, Romania
}

\begin{abstract}
Salt intake is one of the important predictors of hypertension, a widespread chronic disease among adults. Much remains to be known about its causes, especially in the Romanian context, where there is a scarcity of analyses on this particular topic. Its predictors are relevant for public policy in order to evaluate what strategy should be adopted given actual levels of salt intake and the way people think about their levels of salt intake. Our analyses focus on actual and perceived salt intake. Data for this analysis come from the SEPHAR project, gathered in 2016 (wave 3), a nationally representative sample of Romanians. After noting a major discrepancy between perceived and actual levels of salt intake, we used two regressions with actual and perceived salt intake as dependent variables and three types of factors as independent variables: socio-demographic (age, gender, region, type of locality, education), lifestyle (fat diet, alcohol consumption, active lifestyle, and smoking) and related diseases (obesity and diabetes). Results show Romanians have similar levels of salt intake perceptions independently of the characteristics considered, except fat diet and diabetes, and similar levels of actual salt intake except age and gender, even though previous research shows that there are differences between individuals across these characteristics when it comes to considering hypertension as a dependent variable. We conclude bynoting policy interventions regarding salt intake based on the results of this research, especially the need to update the current Romanian TV campaign to reduce salt intake or similar campaigns from other countries.
\end{abstract}

Keywords: Salt intake perceptions, actual salt intake, public policy, SEPHAR, regression

Approximately one in six deaths a year worldwide is caused by complications from hypertension [1]. Among causes of death which can be prevented, hypertension is the leading cause [2] and salt intake holds an important role in nutrition practices for disease prevention [3]. For two conditions, i.e. ischemic heart disease and cerebrovascular disease, Romania has the highest rates in comparison with other countries worldwide, according to the World Health Organization ([1], data from 2008) which released a special report on why hypertension is a major issue and why it should be tackled by public policy. Dorobanu et al. [4] report in 2013 that about $40 \%$ of the Romanian adult population were hypertensive. The World Health Organization [5] offers statistics for gender differences in salt intake in Romania in 2013: on average the daily salt intake for women was 10.2 grams per day and 12.5 grams per day for men, even though current recommendations of salt intake underline the limit of 5-6 grams of salt per day (medical normality $[5,6]$ ).

Salt consumption is documented to be a predictor of hypertension [7,8], a widespread chronic disease among adults [9]. Much remains to be known about its causes, especially in the Romanian context, where there is a scarcity of data and analyses on this particular topic [10]. Its determinants are relevant for public policy in order to identify groups in high need of assistance. Moreover, how people perceive their own saltintake is important for public policy especially because perceptions on a topic predict behaviors with respect to it, as the theory of planned behavior argues [11] and if one perceives a situation to be real, itwill become as such through its consequences [12].
If people do not think their salt intake is high but it is according to medical standards, they would not take any action about reducing their intake, which in turn will affect their health. Also, knowing and understanding that salt intake influences important diseases which cause millions of deaths each year should be leading goals for public policy.

In order to tackle the predictors of actual and perceived salt intake, it is important to consider factors also associated with hypertension, as it is the disease most related to salt intake as a risk factor. Dahl [7] found evidence for differences in salt intake among distinct cultures and regions, underlining the importance of considering the geographical aspect when analyzing this variable. Given that salt intake is connected with hypertension, we assume that predictors of salt intake are also predictors of hypertension. The World Health Organization [1] documents the following factors associated with hypertension: social factors, behavioral risk factors, metabolic risk factors and cardiovascular disease (p. 11). Among the social factors, the authors consider globalization, urbanization, population ageing, income, education, and housing [1]. The behavioral risk factors are unhealthy diet, tobacco use, physical inactivity, and harmful use of alcohol $[1,13]$. Further, the metabolic risk factors considered are high blood pressure, obesity, diabetes, and raised blood lipids [1]. Moreover, cardiovascular diseases, including heart attacks, strokes, heart failure and kidney disease, are other factors which influence hypertension [1]. In terms of gender, men are more likely to have raised blood pressure than women and this trend is found worldwide, but the difference is $10 \%$ at most [ 1 ].

\footnotetext{
* email: corina.bragaru@sas.unibuc.ro, Phone: 0040766564417
} 
Our study is relevant for public policy in terms of initiatives for reducing salt consumption. The World Health Organization [5] documents the Romanian salt reduction initiatives in 2013. The following initiatives are fully implemented: monitoring and evaluation of salt content in food and TV Radio consumer awareness initiatives ${ }^{1}$. The following initiatives are partially implemented: monitoring and evaluation of industry self-reporting, salt intake and consumer awareness, food reformulation as a stakeholder approach, and labelling and brochure print as population approaches. Finally, several initiatives were found by the World Health Organization to have not been implemented at all: monitoring and evaluation of behavioral change and urinary salt excretion ( 24 hours), stakeholder approach of specific food category, and population approaches in terms of consumer awareness initiatives via website software, education, schools, health care initiatives, conferences and reporting [5].

\section{Experimental part \\ Methods \\ Data}

Data for this analysis come from the SEPHAR project, gathered in 2016 (wave 3), a nationally representative sample of Romanians. It contains individual level variables on salt consumption, medical and socio-demographic variables. It is large enough to conduct regression analyses (total $\mathrm{N}=1970$ ) and the results can be generalized through appropriate methods to the general Romanian population.

\section{Variables \\ Actual salt intake is estimated using the Kawasaki} formula [14] based on a sodium urinary test for analyzing the $24 \mathrm{~h}$ sodium in urine. The recommended threshold for salt intake per day is $6 \mathrm{~g}$ [15]. The variable used is coded as: code 0 for equal to or under 6 grams per day and code 1 for over 6 grams per day. Perceptions on salt intake are measured using the question How would you rate the quantity of salt intake in your diet?, coded with 0 l eat food without salt, 1 I eat food with normal quantities of salt, and 2 I eat food with substantial amounts of salt.

Region is included in this analysis as dummy variables, each of them coded with 1 for the current region (one at a time: North-East [NE], South-East [SE], South [S], SouthWest [SW], West [W], North-West [NW], and Center [C]) and 0 for all other situations, considering Bucharest-llfov as the reference category. One reason for choosing this particular reference category is given by the high socioeconomic development of this region in comparison with all other regions $[16,17]$; for details on the technical strategy, see [18]).

Whether the respondent lives in an urban setting ( towns or cities) was coded as 1 and 0 if they live in a rural setting. Gender is coded into 1 for females and 0 for males. Age is included in the analysis with three categories: 1 for 18 to 39 years of age, 2 for 40 to 64 years of age and 3 for 65 years of age or above. Education is coded 1 for high levels (tertiary education) and 0 for medium (secondary education), low (primaryeducation) or withouteducation.

Physical activity is measured ordinally using the following question: How often are you physically active?, coded as 1 sporadic, 2 once a week, 3 two or three times a week, 4 almost every day, and 5 every day. Smoking is included in the questionnaire using the following question:
Are you a smoker?, coded 1 for smokers and 0 for nonsmokers at the moment. With respect to fat diet, we use the following question: What type of food do you usually eat?, coded as 0 for a vegetarian diet, 1 for a diet with low content of fat (eating fish or chicken), and 2 for a fat diet (eating meat of animal origin). Alcohol drinking is measured with the question What quantity of alcohol do you usually drink?, and is coded as 0 without alcohol drinking, 1 with normal quantities of alcohol drinking (less than $300 \mathrm{~mL}$ of wine or $30 \mathrm{~mL}$ of distilled beverages per day) and 2 for higher quantities of alcohol drinking (more than $300 \mathrm{~mL}$ of wine or $30 \mathrm{~mL}$ of distilled beverages per day).

For measuring obesity, we used the definition provided by the World Health Organization which states that obesity can be considered if the Body Mass Index (computed by dividing the weight by the squared height) is equal to or greater than 30 [19]. For this situation, the variable included in the analysis is coded 1 for obesity and 0 else. With respect to diabetes, the question is Have you ever been diagnosed with diabetes?, coded as a dummy variable, with 1 for the presence of the characteristic and 0 for the absence.

\section{Analyses}

Considering that our dependent variables are measured differently, we used an ordinal regression for the model with perceived salt intake and a binary logistic regression for the model with actual salt intake (for more details on the methods, see [20-22]). For dealing with missing data, we replaced the missing values with the median of each variable in order to take into account the level of measurement of the variables included (ordinal or dummy) and the entire range of answers provided by responses (given the listwise method for dealing with missing data included in regressions). For our analysis, we used IBM SPSS statistical software, version 22. Our model is depicted in Figure 1.

\begin{tabular}{l|} 
Socio-demographic factors \\
Lifestyle factors \\
Related diseases
\end{tabular}

Fig. 1. Conceptual diagram

\section{Results and discussions}

\section{Descriptive statistics}

Almostall respondents show higher than recommended levels of actual estimated saltintake at their sodium urinary test. Only 3.2\% show normal levels of salt intake, whereas most respondents consider that they have normal levels of salt intake: $76.5 \%$ of the total sample, while only $9.4 \%$ perceive their saltintake to be athigh levels. The perception values differ from the actual objective values resulting in a high disparity between respondents' thoughts and their actual behavior.

Our sample is composed of $52.5 \%$ of females and $47.5 \%$ males. $36.3 \%$ of respondents are between 18 and 39 years of age, whereas $42.7 \%$ are between 40 and 64 years of age. Concerning regional distributions, the lowest value of $9.9 \%$ is in the West and the highest value in the South, $16.2 \%$. $34.8 \%$ of the total sample is composed of individuals with higher education attainment. In terms of lifestyle, one in six respondents consider they are active

\footnotetext{
${ }^{1}$ In 2006, the National Council for Audio-Video stated that Romanian TV channels must repeat daily a message of awareness regarding high levels of salt consumption: For your health, please avoid salt, sugar and fat consumption in excess [23,28]. This awareness campaign has been implemented throughout this entire period and, currently, at the beginning of 2018, it promotes the same message.
} 
every day and only $8.8 \%$ think that they are active in a sporadic manner. A quarter of the sample is composed of smokers, $6.2 \%$ are vegetarians, $66.2 \%$ have a normal diet, and $27.6 \%$ a fat diet. Concerning alcohol consumption, only $4.7 \%$ report consuming high quantities, while $40.9 \%$ think they do not drink at all. 34.2\% of the total sample are obese, whereas $6.9 \%$ declare having diabetes (Table 1 ).

Table 1

DESCRIPTIVE STATISTICS ( $\mathrm{N}=1970)$

\begin{tabular}{|c|c|}
\hline & $\%$ \\
\hline \multicolumn{2}{|l|}{ Salt intake consumption } \\
\hline 0. Normal & 3.2 \\
\hline 1. High & 96.8 \\
\hline \multicolumn{2}{|l|}{ Salt intake perception } \\
\hline 0. None & 14.1 \\
\hline 1. Normal & 76.5 \\
\hline 2. High & 9.4 \\
\hline \multicolumn{2}{|l|}{ Type of locality } \\
\hline 0. Rural & 41.1 \\
\hline 1. Urban & 58.9 \\
\hline \multicolumn{2}{|l|}{ Gender } \\
\hline 0. Male & 47.5 \\
\hline 1. Female & 52.5 \\
\hline \multicolumn{2}{|l|}{ Education } \\
\hline 0. Low levels & 65.2 \\
\hline \multirow{2}{*}{\multicolumn{2}{|c|}{ Region }} \\
\hline & \\
\hline 1. NE & 10.7 \\
\hline 2. SE & 13.2 \\
\hline 3. $\mathrm{S}$ & 16.2 \\
\hline 4. SW & 11.1 \\
\hline 5. W & 9.9 \\
\hline 6. NW & 14.4 \\
\hline 7. Center & 12.8 \\
\hline 8. Bucharest-Ilfov & 11.6 \\
\hline \multicolumn{2}{|l|}{ 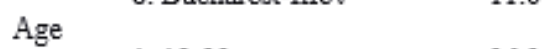 } \\
\hline 1. $18-39$ years & 36.3 \\
\hline 2. $40-64$ years & 42.7 \\
\hline $3.65+$ years & 21.0 \\
\hline \multicolumn{2}{|l|}{ Active lifestyle } \\
\hline 1. sporadic & 8.8 \\
\hline 2. once a week & 3.6 \\
\hline 3. $2 / 3$ times a week11.7 & \\
\hline $\begin{array}{l}\text { 4. almost every day } 10.4 \\
\text { 5. every day }\end{array}$ & 65.5 \\
\hline \multicolumn{2}{|l|}{ Type of diet } \\
\hline 0 . Vegetarian & 6.2 \\
\hline 1. Normal diet & 66.2 \\
\hline 2. Fat diet & 27.6 \\
\hline \multicolumn{2}{|l|}{ Smoking } \\
\hline 0. No & 75.5 \\
\hline 1. Yes & 24.5 \\
\hline \multicolumn{2}{|l|}{ Diabetes } \\
\hline 0. No & 93.1 \\
\hline 1. Yes & 6.9 \\
\hline \multicolumn{2}{|l|}{ Obesity } \\
\hline 0. No & 65.8 \\
\hline 1. Yes & 34.2 \\
\hline \multicolumn{2}{|l|}{ Alcohol consumption } \\
\hline 0. Without alcohol 40.9 & \\
\hline 1. Normal quantity 54.4 & \\
\hline 2. Raised quantity 4.7 & 1970 \\
\hline
\end{tabular}

\section{Bivariate statistics}

Considering the huge difference between actual salt intake and perceived salt intake, we take a look at their distributions across socio-demographic factors in order to see differences between regions, type of locality, age, gender and education groups (Table 2). Differences between each group are low, under $10 \%$, independently of the characteristic considered, and the descriptive patterns stating that the majority of Romanians have normal levels of perceived salt intake, but high actual levels are kept the same across socio-demographic characteristics. Our research shows that the TV campaign [23] might not be efficient given the targeted public and, instead, another campaign focusing on what medical normality means (i.e. 5-6 grams per day) and how different it is from perceived saltintake should be considered.

\section{Multivariate statistics}

Except for fat diet and diabetes, for perceptions of salt intake none of the independent variables considered is statistically significant (Table 3), whereas for actual salt intake only age and gender are statistically significant (Table 4). Net of all other variables included in the first model, respondents with diabetes declare that they eat lower levels of salt than those without diabetes and those who have a fat diet are more likely to have higher levels of salt intake. In the second model, net of all other variables included, men and older persons have higher levels of salt intake in sodium urinary test than women and younger persons respectively. Fat diet and diabetes are not statistically significant in the second model. The results show that, with respect to perceived levels of salt intake, in the first model, there are no statistically significant differences between men and women or between younger and older persons. Also, in both models, there are no differences between respondents from rural and urban environments, between highly educated individuals and those with lower levels of education, between those who are physically active and others, between smokers and non-smokers, between those who report that they are overweight and others, and independently of the levels of alcohol consumption.

For the first model, pseudo R-square shows values of 0.049 (McFadden coefficient), 0.066 (Cox and Snell coefficient) and 0.088 (Nagelkerke coefficient), meaning that $8.8 \%$ at most of the variance in the dependent variable is explained by the model. For the second model, Nagelkerke R-square coefficientis 0.177 and Cox and Snell R-square coefficient is 0.044 , meaning that $17.7 \%$ at most of the variance in the dependent variable is explained by the model.

Because salt consumption influences hypertension [7], our results are relevant for public policy especially in the context of promoting health behaviors. Riet, Ruiter, Smerecnik, and Vries [24] stress the importance of considering individual self-efficacy for the effectiveness of campaigns for promoting reduction of salt intake, in the sense that for individuals with high self-efficacy the saltreducing messages will have a higher impact than for those with low self-efficacy. This concept, in line with the theory

\footnotetext{
${ }^{2}$ Before running the analyses, we considered the national data from the National Institute of Statistics (2017) [29], at January 1st 2015. We found differences between categories of gender and age and constructed and applied to the results presented in the paper a weight in order to adjust the sample. For individuals of 18 years of age or older, $51.7 \%$ were women, which shows a difference of 0.8 between our sample and the national one (52.5\% of our respondents). With respect to age, $36.3 \%$ of Romanians (34\% of our respondents) were between 18 and 39 years of age, $42.7 \%$ ( $43 \%$ of our respondents) were between 40 and 64 years of age and $20.9 \%$ (23\% of our respondents) were 65 years of age or older. Differences between our sample and the National Institute of Statistics data tended to be small, amounted to 1-2\% at most, and give us even greater reason to believe that our sample is representative of the adult population of Romania.
} 


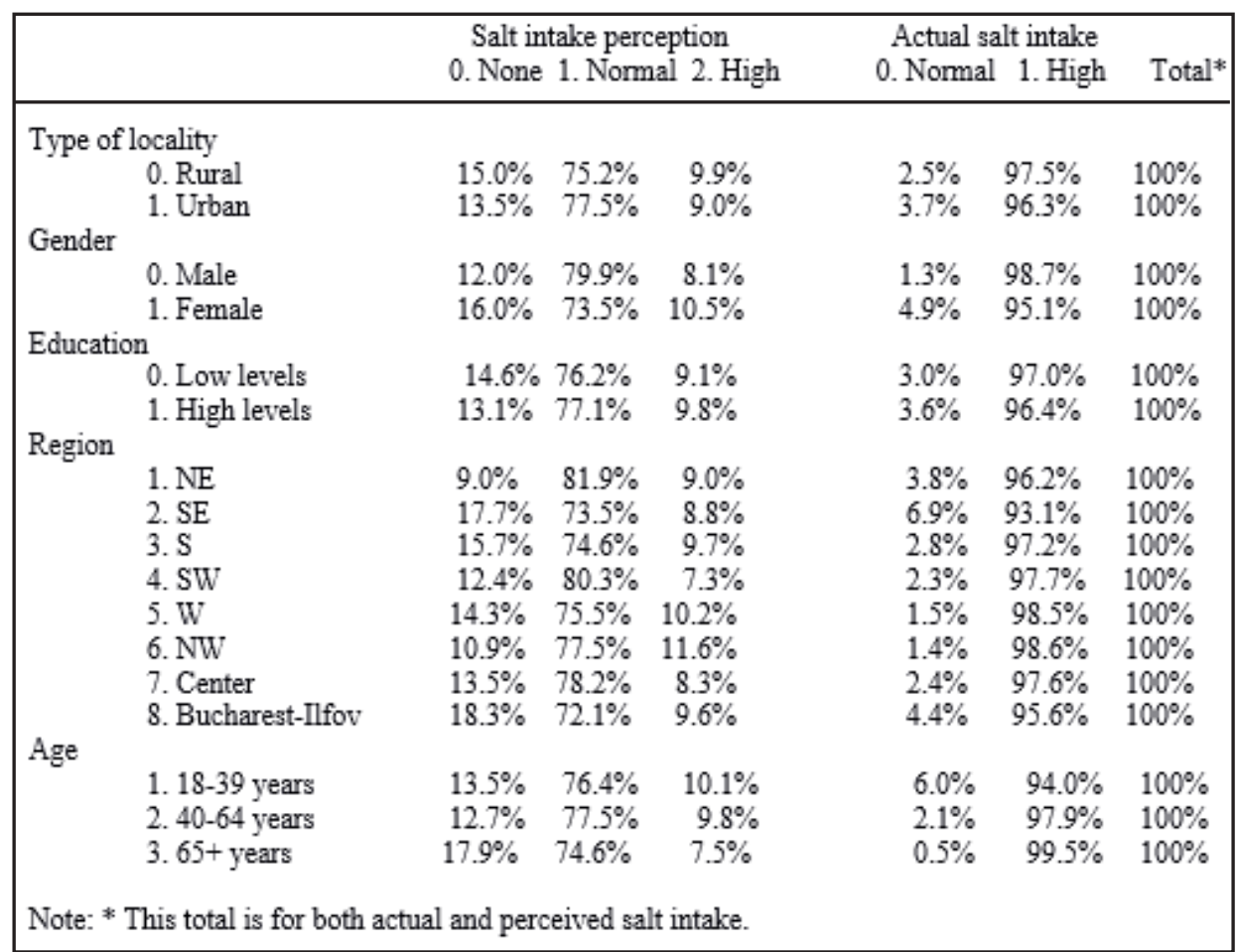

Table 2

BIVARIATE STATISTICS BETWEEN SOCIO-DEMOGRAPHIC FACTORS AND ACTUAL AND PERCEIVED SALT INTAKE $(\mathrm{N}=1970)$
Table 3

MULTIVARIATE RESULTS OF THE MODEL FOR THE PERCEPTION ON SALT INTAKE, Sig.<0.001

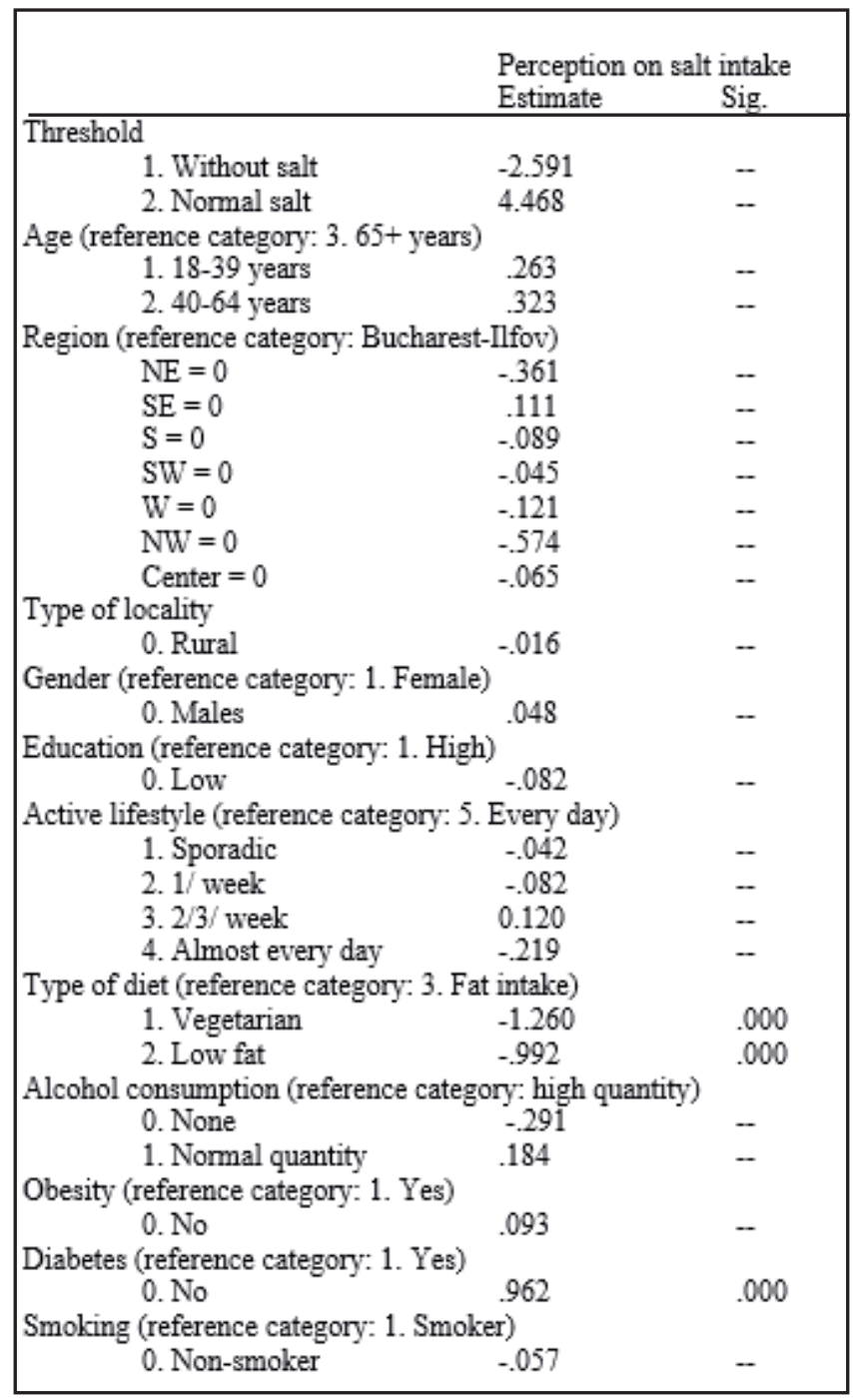

of planned behavior, was also considered by Cornelio et al. [8]. Our dataset does not contain variables measuring the concept, but we think that further studies would benefit if they contained or introduced such variables.

Policy interventions should consider predictors of salt intake in their initiatives. They should take into account the patterns revealed by our analysis in order to develop cost effective interventions $[1,25]$, such as monitoring and evaluation programs, consumer awareness campaigns and targeted projects. In Romania, we find similar levels of salt intake independently of the characteristics considered, except fat diet and diabetes for perceptions of salt intake and gender and age for actual estimated salt intake, even though previous research shows that there are differences between individuals across these characteristics when it comes to considering hypertension as a dependent variable.

Our results are key for public policy in terms of developing initiatives for saltreduction. We found that most of the respondents consider that they have normal levels of salt intake, but the actual tests show that almost all of them have higher than recommended levels of actual salt intake. This is an interesting and important result per se. Moreover, our analyses showed only small differences between types of respondents, which means that salt reduction campaigns can target widespread types of people across the country. The TV campaign [23] focusing on salt reduction may not be efficient given the characteristics of the targeted population: people with high levels of actual salt intake (medical abnormality), but who perceive themselves to have normal levels of salt intake. If people think they have normal levels of salt intake, when they hear the TV message about salt reduction they do not feel this message is addressed to them, even though it actually is. This reproduces the dictum stating that if a situation is perceived as real, it will become as such through its consequences [12], keeping high levels of salt intake. The TV message should be focused on other pieces of information than salt reduction, especially on what medical normality means, i.e. 5-6 g of salt per day at most, and what the actual salt intake looks like in Romania. 
Table 4

MULTIVARIATE RESULTS OF THE MODEL FOR THE ACTUAL ESTIMATED SALT INTAKE, Sig. $<0.001$

\begin{tabular}{|lll|}
\hline & \multicolumn{2}{c|}{ Actual estimated salt intake } \\
& Estimate & Sig. \\
\hline Constant & 2.482 & - \\
Age & 1.035 & .000 \\
Region (reference category: Bucharest-Ilfov) & \\
NE & -.050 & - \\
SE & -.644 & - \\
S & .354 & - \\
SW & .352 & - \\
\multicolumn{1}{|c|}{ NW } & .886 & - \\
Center & 1.070 & - \\
Type of locality & .576 & - \\
Gender & -.460 & - \\
Education & -1.647 & .000 \\
Active lifestyle & .232 & - \\
Type of diet & .016 & - \\
Alcohol consumption & .143 & - \\
Obesity & .256 & - \\
Diabetes & .466 & - \\
Smoking & 1.669 & - \\
& -.553 & - \\
\hline
\end{tabular}

Simple messages inviting the audience to reduce salt can be found in other countries as well, for example the Go easy on salt campaign developed by the Stroke Foundation in New Zealand [26, 27]. The message is not accompanied by weight limits for actual salt intake, same as in the Romanian TV campaign. However, the message is not accompanied by weight limits for actual salt intake, as is true for the Romanian TV campaign.

Acknowledgements: The authors wish to express their gratitude to the team of the SEPHAR study (http://www.sephar.ro/) for the data used in this article.

\section{Refernces}

1 *** WORLD HEALTH ORGANIZATION: A global brief on hypertension: Silent killer, global public health crisis 2013 [ cited 2018] an 27];Available from:http://ish-world.com/dow nloads/pdf/global_brief_ hypertension.pdf

2 MILLS KT, BUNDY JD, KELLY TN, REED JE, KEARNEY PM, REYNOLDS $K$, et al.: Global disparities of hypertension prevalence and control: A systematic analysis of population-based studies from 90 countries. Circulation 2016;134:441-450.

3 CHAN M: Foreword. A Glob Br Hypertens Silent Kill Glob public Heal Cris 2013 [cited 2018 Jan 27];5.

4 DOROBANTU M, DARABONT R, GHIORGHE S, ARSENESCUGEORGESCU C, MACARIE C, MITU F, et al.: Hypertension prevalence and control in Romania at a seven-year interval. Comparison of SEPHAR I and II surveys. J Hypertens 2013;32:39-47.

5 *** WORLD HEALTH ORGANIZATION: Nutrition, Physical Activity and Obesity: Romania 2013 [cited 2018 ] an 27];Available from: http:// www.euro.who.int/_data/assets/pdf_file/0014/243320/Romania-WHOCountry-Profile.pdf?ua $=1$

6 HULTHEN L, AURELL M, KLINGBERG S, HALLENBERG E, LORENTZON M, OHLSSON C: Salt intake in young Swedish men. Public Health Nutr 2009;13:601-605.

7 DAHL LK: Possible role of salt intake in the development of essential hypertension. Int J Epidemiol 2005;34:967-972.

8 CORNEELIO ME, GALLANI M-CBJ, GODIN G, RODRIGUES RCM, NADRUZ JR W, MENDEZ RDR: Behavioural determinants of salt consumption among hypertensive individuals. J Hum Nutr Diet 2012;25:334-344.

9 DOROBANTU M, DARABONT R, GHIORGHE S, BABES K, POP D, TOMA D, et al.: Profile of the Romanian Hypertensive Patient Data from SEPHAR II Study. Rom J Intern Med 2012;50:285-296.
10 DOROBANTU M, BARTO` D, APETREI E, ARSENESCU-GEORGESCU C, POP D, GHIORGHE S, et al.: Hypertension in Romania: where are we and what can we do? Results from SEPHAR II study. Rom J Cardiol 2012;22:285-292.

11 AJZEN I: The Theory of Planned Behavior. Organ Behav Hum Decis Process 1991;50:179-211.

12THOMAS WI, THOMAS DS: The child in America: Behavior problems and programs. New York, Knopf, 1928.

13 PARK JE, JUNG H, LEE JE: Dietary pattern and hypertension in Korean adults. Public Health Nutr 2013;17:597-606.

14 KAWASAKI T, ITOH K, UEZONO K, SASAKI H: A simple method for estimating $24 \mathrm{~h}$ urinary sodium and potassium excretion from second morning voiding urine specimen in adults. Clin Exp Pharmacol Physiol 1993;20:7-14.

15 MANCIA G, FAGARD R, NARKIEWICZ K, REDON J, ZANCHETTI A, BOHM M, et al.: 2013 ESH/ESC Guidelines for the management of arterial hypertension: The Task Force for the management of arterial hypertension of the European Society of Hypertension (ESH) and of the European Society of Cardiology (ESC). J Hypertens 2013;31:12811357.

16 IONESCU-HEROIU M, BURDUJA SI, SANDU D, COJOCARU S, BLANKESPOOR B, IORGA E, et al.: Competitive cities: reshaping the economic geography of Romania. Washington, DC, 2013.Available from:http://ww w-wds.w orldbank.org/external/d efault/ WDSContentServer/WDSP/IB/2014/03/04/000350881_20140304103607/ Rendered/PDF/843240v10ROMAN0ompetitiveORaport0RO.pdf

17 VLASCEANU L, HANCEAN M-G: Modernitatea romaneasca. Pitesti, Paralela 45, 2014.

18 GRACE-MARTIN K: Strategies for Choosing the Reference Category in Dummy Coding 2016 [cited 2018 J an 27];Available from: http:// www.theanalysisfactor.com/strategies-dummy-coding/

19*** W ORLD HEALTH ORGANIZATION: Body mass index - BMI 2018 [cited 2018J an 27];Available from: http://www.euro.who.int/en/healthtopics/disease-prevention/nutrition/a-healthy-lifestyle/body-massindex-bmi

20 FOX J: Applied regression analysis and generalized linear models. ed 2nd Los Angeles, Sage, 2008.

21 HARDY MA: Regression with dummy variables. Newbury Park, California, Sage Publications, Inc., 1993.

22 VASILE M: Introducere în SPSS pentru cercetarea sociala si de piata: o perspectiva aplicata. lasi, Polirom, 2014.

23*** CONSILIUL NATIONAL AL AUDIOVIZUALULUI: Campania Pentru un stil de viata sanatos, initiata de CNA si International Advertising Association (IAA) 2009 [cited 2018 Jan 27];Available from: http:// www.cna.ro/article2521,2521.html

24 RIET J P VAN 'T, RUITER RAC, SMERECNIK C, VRIES H DE: Examining the influence of self-efficacy on message-framing effects: Reducing salt consumption in the general population. Basic Appl Soc Psych 2010;32:165-172.

25 SCHORLING E, NIEBUHR D, KROKE A: Cost-effectiveness of salt reduction to prevent hypertention and CVD: a systematic review. Public Health Nutr 2017; DOI: 10.1017/S1368980017000593

$26 * * *$ STROKE FOUNDATION: Go easy on salt! [cited $2018 \mathrm{Mar}$ 22];Available from: https://www.stroke.org.nz/resources/Go Easy on SALT poster_0.pdf

27 *** STROKE FOUNDATION, Food Smart, Consumer: Slash the salt [cited 2018 Mar 22];Available from: https://www.stroke.org.nz/ resources/slash-the-salt.pdf

28 *** CONSILIUL NAIONAL AL AUDIOVIZUALULUI: Fostul Cod audiovizual care a fost în vigoare pana la data de 10 martie 2011 (Decizia nr. 187 din 3 aprilie 2006) 2011 [cited 2018 J an 27]; Available from: http://www.cna.ro/Decizia-nr-nr-187-din-3-aprilie.html

$29 * * *$ INSTITUTUL NATIONAL DE STATISTICA: Populatie si structura demografica 2017 [cited 2018 Jan 27]; Available from: http:// statistici.insse.ro/shop/

Manuscript received: 2006.2018 